\author{
І.А. Кулик, М.С. Шевченко \\ Сумський державний університет, Суми
}

\title{
МАТРИЧНА МОДЕЛЬ СКЛАДАННЯ ДВІЙКОВИХ БІНОМІАЛЬНИХ ЧИСЕЛ
}

У статті пропонується матрична модель складання біноміальних чисел, які генеруються двійковими біноміальними системами числення. Модель біноміального складання використовує матричне подання чисел $i$ перетворення перенесення, зрушення, симетрії, розкладання над вмістом осередків матриці підсумовування, кожна з яких відповідає ваговому коефіцієнту біноміальної числової функції. Зазначені перетворення засновані на відомих комбінаторних співвідношеннях. Наведені моделі арифметичних дій над кодами-сполученнями на основі реалізації додавання і множення двійкових біноміальних чисел.

Ключові слова: двійкові біноміальні числа, біноміальна арифметика, матричя біноміального складання, перетворення осередків матрииі.

\section{Вступ}

Постановка проблеми. Значний науковопрактичний інтерес представляє собою використання в інформаційно-керуючих системах нетрадиційних спеціалізованих систем числення, які на відміну від двійкової системи чисел, мають додаткові позитивні властивості. Очевидно, що двійкова система числення у багатьох випадках не в змозі задовольняти підвищені вимоги до продуктивності або відмовостійкості інформаційно-керуючих систем без залучення додаткових, достатньо дорогих апаратних та/або програмних витрат [1-4].

Перспективне розв'язання суперечностей, які пов'язані 3 підвищенням продуктивності без зниження відмовостійкості і навпаки, можливо на шляху застосування структурних позиційних систем числення, таких, як фібоначчієві, факторіальні або біноміальні системи числення [5-7]. Завдяки своїй вихідній структурі і природним властивостям структурних чисел, які ними генеруються, вони здатні досить просто організовувати самоконтроль оброблюваної інформації, усувати надмірність в повідомленнях, генерувати різноманітні комбінаторні об'єкти, на що двійкові системи числення самі по собі не здатні.

У зв'язку з цим особливу привабливість мають біноміальні системи числення, зокрема двійкові біноміальні, через простоту генерування двійкових біноміальних чисел і поширеність кодових комбінацій, в основі структури яких лежать біноміальні коефіцієнти [8-9]. До таких широко розповсюджених кодових комбінацій відносяться рівноважні і квазірівноважні коди, коди з обмеженнями на розташування нулів і одиниць в розрядній сітці і багато подібних.

Згідно 3 концепцією розробки інформаційнокеруючих систем на базі двійкових біноміальних систем числення, двійкові біноміальні числа можуть застосовуватися в роботі інформаційних систем в цілому, або локально в її структурі, для вирішення спеціалізованих завдань, наприклад стиснення інформації або іiі шифрування, комбінаторної оптимізації та нумераційного кодування [7].

Але впровадження інформаційної технології обробки інформації на основі двійкових біноміальних чисел стикається 3 серйозною перешкодою відсутністю розробленої машинної арифметики для двійкових біноміальних систем числення. 3 огляду на наявну складну залежність вагових коефіцієнтів не тільки від розрядних позицій цифр в біноміальному числі, але і від значень попередніх цифр, отримання біноміальної арифметики є важким завданням. Її вирішення дозволить істотно розширити функціональні можливості біноміальних систем чисел, отримати нові методи по обробці двійкової інформації, іiі завадостійкому або економному кодуванню, спростити вирішення низки задач комбінаторної оптимізації та генерування різних комбінаторних об'єктів.

Наприклад, генерування рівноважних кодів в заданому або довільному порядку являє собою досить складне завдання, особливо для багаторозрядних кодових комбінацій [10-11]. Цей процес може бути кратне прискорений та спрощений, якщо від рівноважних комбінацій переходити до відповідних їм біноміальних чисел, далі складати 3 заданими іншими біноміальними числами, а отримані результати підсумовування приводити вже до затребуваних рівноважних послідовностей.

У даній роботі буде розглядатися науковий підхід до створення машинної біноміальної арифметики, математичних моделей представлення двійкових біноміальних чисел та їх складання, послідовність дій для отримання результату додавання чисел. На основі операції складання можна побудувати всі інші арифметичні операції над двійковими біноміальними числами: віднімання, множення і ділення. 
Аналіз останніх досягнень і публікацій. Відомо, що будь-яка ефективна система числення повинна забезпечувати виконання арифметичних операцій над числами, які вона генерує [2-3; 12].

Розробка основ арифметики для фібоначчієвої системи числення стало суттєвим етапом у розвитку проекту "Комп'ютер Фібоначчі", а також у створенні самоконтролюючих і самокорегуючих обчислювальних і вимірювальних пристроїв та систем на основі кодів Фібоначчі [5; 13-14].

Наявність розроблених процедур проведення арифметичних операцій над факторіальними числами в факторіальній системі числення дозволило помітно знизити часові витрати на генерування перестановок в довільному і заданому порядках, а також спростити технічну реалізацію відповідних факторіальних пристроїв і систем на практиці [15-16].

У системах залишкових класів наявність арифметичних операцій, що виконуються покомпонентно, дозволяє домогтися високої швидкості вирішення спеціалізованих завдань над цілочисельними даними в системах цифрової обробки сигналів, обробки цифрових зображень, контролю та діагностики, криптографічних системах і т.д. [17-18].

У порівнянні з фібоначчієвими і факторіальними числами біноміальні мають більш складну структуру, але в той же час є більш перешкодостійкими, здатними до виявлення і виправлення більшого виду і кількості помилок. Позиційний характер залежності вагових коефіцієнтів біноміальних чисел відносно непозиційних систем залишкових класів істотно спрощує переходи від біноміальних чисел до двійкових і навпаки, а також робить простішим проведення операцій порівняння між біноміальними числами. Очевидно, що переваги біноміальних систем числення при наявності біноміальної арифметики мали б помножуючий ефект при використанні біноміальних чисел в інформаційно-керуючих системах різного призначення.

Але для біноміальних систем числення завдання проведення арифметичних операцій над біноміальними числами, відмінними від одиниці, поки що вирішена на рівні пропонованих концепції і наукового підходу [19]. На сьогоднішній день детально розробленими є тільки теорія і практика біноміального рахунку, що додатковим чином підтверджує існування повноцінної біноміальної арифметики вказує на можливість тї розробки для біноміальних чисел, зокрема двійкових біноміальних.

В роботі [9] наведені алгоритми біноміального рахунку, що підсумовують та віднімають одиницю, як для нерівномірних, так і рівномірних чисел, разом 3 практичним додатком про ефективне застосування розроблених алгоритмів для перебору рівноважних кодових комбінацій. В роботі [8] для вищевказаних алгоритмів сформульовані теоретично до- ведені твердження, які розкривають порядкові властивості двійкових біноміальних чисел.

Практична реалізація алгоритмів біноміального рахунку розглядається в роботі [20] у вигляді підсумовуючих і віднімаючих рахункових пристроїв. Наведені в роботі технічні рішення пройшли експертизу на практиці і захищені відповідними авторськими свідоцтвами та патентами.

Теоретичні та практичні результати в розглянутих роботах, на жаль, відносяться тільки до збільшення чи зменшення значень біноміальних чисел на одиницю, що однозначно не може замінити необхідність розробки машинної біноміальної арифметики, зокрема біноміального підсумовування, і не знижує актуальності їх впровадження в практику застосування інформаційних технологій по обробці даних на основі двійкових біноміальних чисел.

Мета статті - підвищення швидкодії інформаційно-керуючих систем, комп'ютерних систем i компонентів, які використовують двійкові біноміальні числа для рішення спеціалізованих завдань по комбінаторному стисненню та шифруванню даних, завадостійкому кодуванню і передачі інформації, генеруванню різних комбінаторних об'єктів. Засобами досягнення зазначеної мети є подальший розвиток теорії двійкових біноміальних систем числення та інформаційної технології обробки даних на їх основі шляхом створення математичної моделі і алгоритмів складання двійкових біноміальних чисел.

Областю призначення науково-практичних результатів роботи є як спеціалізовані біноміальні пристрої та системи, так і комп'ютерні системи універсального характеру, які використовують для вирішення інформаційних завдань двійкові біноміальні системи числення.

\section{Виклад основного матеріалу}

\section{Моделі арифметичних дій над кодами-сполученнями}

Числова функція двійкової $(n, k)$-біноміальної системи числення, яка визначає десятковий еквівалент $F_{j}$ двійкового біноміального числа $X_{j}$, має наступний вигляд [7;21]:

$$
F_{j}=\operatorname{dec} X_{j}=\sum_{i=1}^{r} x_{i} C_{n-i}^{k-q_{i}},
$$

а кодоутворюючі обмеження для формування двійкових $(n, k)$-біноміальних чисел:

$$
\left\{\begin{array} { l } 
{ l = n - k } \\
{ x _ { r } = 0 }
\end{array} \text { та } \left\{\begin{array}{l}
q=k \\
x_{r}=1,
\end{array}\right.\right.
$$

де $n$ і $k$ - параметри $(n, k)$-біноміальної системи числення, $q$ і $l$-кількості двійкових одиниць і нулів в двійковому $(n, k)$-біноміальному числі $X_{j}$, а 
$q_{i}=\sum_{t=1}^{i-1} x_{t}-$ сума одиничних цифр $x_{i}$ від першого розряду до $(i-1)$-го включно.

Бієктивні біноміальні відображення виду $\varphi: X[n, k] \rightarrow Y\left[R_{Y}\right]$ та $\varphi^{-1}: Y\left[R_{Y}\right] \rightarrow X[n, k]$ визначають пряме і зворотне відображення множини $X=X[n, k]$ двійкових $(n, k)$-біноміальних чисел $X_{j}$ на множину $Y=Y\left[R_{Y}\right]$ кодів-сполучень $Y_{j}$ із заданим обмеженням $R_{Y}$. У свою чергу, бієктивні біноміальні відображення виду $\psi: X[n, k] \rightarrow F$ та $\psi^{-1}: F \rightarrow X[n, k]$ визначають пряме та зворотне відображення множини $X[n, k]$ двійкових $(n, k)$ біноміальних чисел $X_{j}$ на множину $F$ номерів $F_{j}$, обчислюваних за числовою функцією (1) [7; 22].

Скористаємося теоретико-множинним підходом, який арифметичні дії задає як особливі відносини між трійками елементів, в яких один елемент визначається через два інших, або як алгебраїчні операції [23-24].

Задамо на множині $X$ двійкових $(n, k)$ біноміальних чисел $X_{j}$ бінарні операції $\omega_{+}$складання і $\omega_{\times}$множення, які вектору $\left(X_{1}, X_{2}\right) \in X^{(2)}$ ставлять у відповідність єдиний елемент $X_{3} \in X$ :

$$
\omega_{+}: X^{(2)} \rightarrow X, \omega_{\times}: X^{(2)} \rightarrow X .
$$

Множина операцій $\omega_{+}$i $\omega_{x}$, заданих на множині $X$, представляє собою сигнатуру двійкових $(n, k)$-біноміальних чисел $\Omega=\left\{\omega_{+}, \omega_{\times}\right\}$.

Таким чином, множина $X$ з їі сигнатурою $\Omega$ визначають біноміальну алгебру $\mathrm{A}(X ; \Omega)$, або алгебру двійкових $(n, k)$-біноміальних чисел $X_{j} \in X$. При цьому надалі арифметичні операції $\omega_{+}$та $\omega_{x}$ будемо позначати або, застосовуючи функціональний запис, або у вигляді спеціальних знаків $+\mathrm{i} \times$ :

$$
\begin{aligned}
& \omega_{+}\left(X_{1}, X_{2}\right)=X_{1}+X_{2}=X_{3}, \\
& \omega_{\times}\left(X_{1}, X_{2}\right)=X_{1} \times X_{2}=X_{3} .
\end{aligned}
$$

Очевидно, що відображення $\psi: X[n, k] \rightarrow F$ i $\psi^{-1}: F \rightarrow X[n, k]$ володіють властивостями:

$$
\begin{aligned}
& \psi\left(X_{1}+X_{2}\right)=\psi\left(X_{1}\right)+\psi\left(X_{2}\right), \\
& \psi\left(X_{1} \times X_{2}\right)=\psi\left(X_{1}\right) \times \psi\left(X_{2}\right), \\
& \psi^{-1}\left(F_{1}+F_{2}\right)=\psi^{-1}\left(F_{1}\right)+\psi^{-1}\left(F_{2}\right), \\
& \psi^{-1}\left(F_{1} \times F_{2}\right)=\psi^{-1}\left(F_{1}\right) \times \psi^{-1}\left(F_{2}\right)
\end{aligned}
$$

відносно бінарних операцій $\omega_{+}, \omega_{\times} \mathrm{i}$, отже, вони визначають ізоморфізм алгебри $\mathrm{A}(X ;+, \times)$ двійкових $(n, k)$-біноміальних чисел $X_{j}$ i алгебри $\mathrm{B}(F ;+, \times)$ двійкових номерів $F_{j}$.

3 урахуванням взаємно однозначної функціональної відповідності $G \subseteq X \times Y$, у якій для кожного $X_{j}$ є єдиний образ $Y_{j}$, а для кожного $Y_{j}-\epsilon д и-$ ний прообраз $X_{j}$, таких, що $\left(X_{j}, Y_{j}\right) \in G$, $X_{j} \in X[n, k]$ та $Y_{j} \in Y\left[R_{Y}\right]$, визначається також ізоморфізм алгебри $\mathrm{A}(X ;+, \times)$ двійкових $(n, k)$ біноміальних чисел $X_{j}$ і алгебри $\Gamma(Y ;+, \times)$ кодівсполучень $Y_{j}$. Це означає, що $\varphi: X[n, k] \rightarrow Y\left[R_{Y}\right]$ та $\varphi^{-1}: Y\left[R_{Y}\right] \rightarrow X[n, k]$ також володіють властивостями:

$$
\begin{aligned}
& \varphi\left(X_{1}+X_{2}\right)=\varphi\left(X_{1}\right)+\varphi\left(X_{2}\right), \\
& \varphi\left(X_{1} \times X_{2}\right)=\varphi\left(X_{1}\right) \times \varphi\left(X_{2}\right), \\
& \varphi^{-1}\left(Y_{1}+Y_{2}\right)=\varphi^{-1}\left(Y_{1}\right)+\varphi^{-1}\left(Y_{2}\right), \\
& \varphi^{-1}\left(Y_{1} \times Y_{2}\right)=\varphi^{-1}\left(Y_{1}\right) \times \varphi^{-1}\left(Y_{2}\right) .
\end{aligned}
$$

Без порушення спільності моделей арифметичних дій над двійковими $(n, k)$-біноміальними числами множину $X$ при подальшому розгляді будемо представляти замкнутою відносно операцій $\omega_{+}$та $\omega_{x}$, тобто

$$
\omega_{+}\left(X^{(2)}\right) \subseteq X, \omega_{\times}\left(X^{(2)}\right) \subseteq X .
$$

Іншими словами, при виконанні арифметичних дій над двійковими $(n, k)$-біноміальними числами параметр $n$ буде зберігати своє значення, що означає ситуацію, коли переноси при виконанні бінарних операцій $\omega_{+}$і $\omega_{x}$ не відбуваються.

Таким чином, з урахуванням взаємно однозначності біноміальних прямого $\varphi$ та зворотного $\varphi^{-1}$ відображень, а також ізоморфізму алгебр $\mathrm{A}(X ;+, \times)$ і $\Gamma(Y ;+, \times)(3)-(6)$, математичними моделями процесів складання i множення кодів-сполучень $Y_{j} \in Y\left[R_{Y}\right]$ як составних процесів біноміального перетворення даних в інформаційно-керуючих системах є наступні співвідношення:

для складання -

$$
\varphi\left(\omega_{+}\left(\varphi^{-1}\left(Y_{1}\right), \varphi^{-1}\left(Y_{2}\right)\right)\right)=Y_{3}
$$

для множення -

$$
\varphi\left(\omega_{\times}\left(\varphi^{-1}\left(Y_{1}\right), \varphi^{-1}\left(Y_{2}\right)\right)\right)=Y_{3}
$$


де $Y_{1}, Y_{2}$ - вихідні доданки (7) або множники (8), представлені кодами-сполученнями, $Y_{1}, Y_{2} \in Y\left[R_{Y}\right]$; $Y_{3}$ - результат складання (7) або множення (8), представлений також у вигляді коду-сполучення, $Y_{3} \in Y\left[R_{Y}\right]$.

Моделі процесів складання (7) і множення (8) реалізуються за допомогою наступних алгоритмічних кроків.

Крок 1. Визначаються образи $X_{1}$ i $X_{2}$ кодівсполучень $Y_{1}$ і $Y_{2}$ при зворотному біноміальному відображенні $\varphi^{-1}: Y\left[R_{Y}\right] \rightarrow X[n, k]:$

$$
\left[\begin{array}{l}
\varphi^{-1}\left(Y_{1}\right)=X_{1}, \\
\varphi^{-1}\left(Y_{2}\right)=X_{2} .
\end{array}\right.
$$

Крок 2. Здійснюються операції складання (множення) над двійковими $(n, k)$-біноміальними числами $X_{1}$ i $X_{2}, X_{1}, X_{2} \in X[n, k]$ :

$$
\omega_{+}\left(X_{1}, X_{2}\right)=X_{3} \text { або } \omega_{\times}\left(X_{1}, X_{2}\right)=X_{3},
$$

враховуючи, що

$$
\omega_{+}\left(X^{(2)}\right) \subseteq X, \omega_{\times}\left(X^{(2)}\right) \subseteq X
$$

Крок 3. Визначається образ $Y_{3}$ двійкового $(n, k)$-біноміального числа $X_{3}$ при прямому біноміальному відображенні $\varphi: X[n, k] \rightarrow Y\left[R_{Y}\right]:$

$$
\varphi\left(X_{3}\right)=Y_{3},
$$

котрий і є результатом складання (множення) кодівсполучень $Y_{1}$ і $Y_{2}, Y_{1}, Y_{2}, Y_{3} \in Y\left[R_{Y}\right]$.

В графічному вигляді моделі арифметичних дій $\omega_{+}$i $\omega_{\times}$над кодами-сполученнями $Y_{j} \in Y\left[R_{Y}\right]$ представлені на рис. 1 .

Представлені моделі $є$ ефективними 3 точки зору швидкодії обробки комбінацій кодів-сполучень і розширення функціональних можливостей застосування двійкових $(n, k)$-біноміальних чисел. Але вони можуть бути реалізовані на практиці тільки при побудові моделей i алгоритмів біноміальних додавання і множення, а також моделей і алгоритмів інших арифметичних операцій над біноміальними числами в двійкових $(n, k)$-біноміальних системах числення.
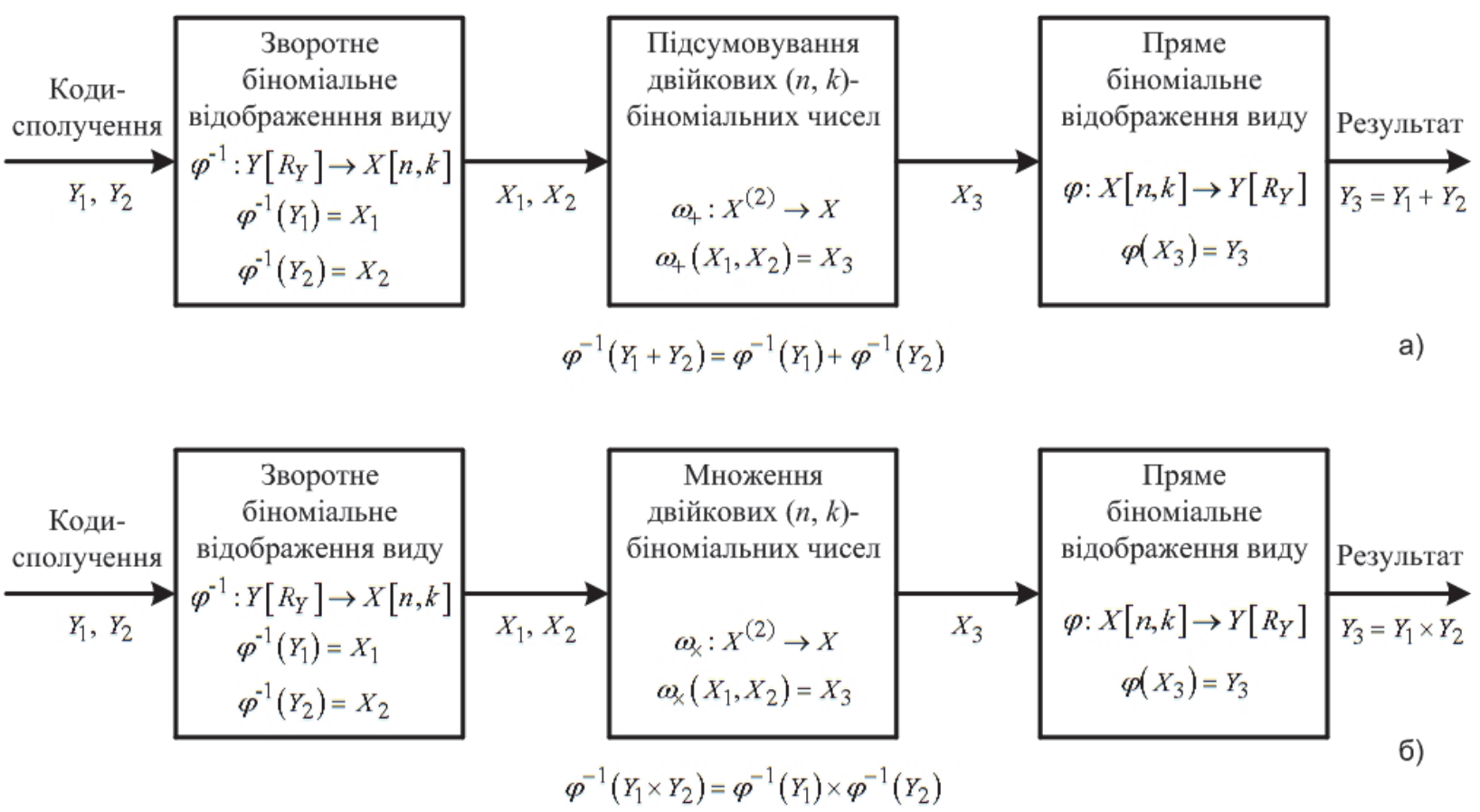

Рис. 1. Моделі процесів а - складання і б - множення двійкових біноміальних чисел Джерело: розроблено авторами.

\section{Матрична модель біноміального складання}

Для розробки математичної моделі складання біноміальних чисел необхідно побудувати і обгрунтувати зручні, тобто придатні до застосування моделі самих двійкових біноміальних чисел.
У зв'язку з цим вагові коефіцієнти з біноміальної числової функції (1) представимо через верхній $\alpha_{i}=k-q_{i}$ та нижній $\beta_{i}=n-i$ параметри:

$$
C_{n-i}^{k-q_{i}}=C_{\beta_{i}}^{\alpha_{i}},
$$

a значення довжини для усіх двійкових $(n, k)$ - 
біноміальних чисел $r=n-1$, тобто оперуємо 3 рівномірними біноміальними числами $X=x_{1} x_{2} \ldots x_{i} \ldots x_{n-1}$, котрі виходять 3 нерівномірних шляхом додавання до $r$-го розряду $(n-r-1)$ двійкових нулів. Таким чином, $є$ множина двійкових біноміальних чисел виду:

$X=\left\{X_{j}=x_{1} x_{2} \ldots x_{i} \ldots x_{n-1} / \sum_{i=1}^{n-1} x_{i} \leq k, 0 \leq F_{j} \leq C_{n}^{k}-1\right\}$.

Пари верхніх та нижніх параметрів $\alpha_{i}$ і $\beta_{i}$ однозначно визначають значення вагових коефіцієнтів $C_{\beta_{i}}^{\alpha_{i}}$ числової функції (1). Відповідно до цього для ïx подання пропонується використовувати двоелементні кортежі виду $\left(\alpha_{i}, \beta_{i}\right)$. Різниця $\Delta_{i}=\beta_{i}-\alpha_{i}$ є зміщення параметрів вагових коефіцієнтів двійкових біноміальних чисел. Звідси, записи кортежів $\left(\alpha_{i}, \beta_{i}\right)$ та $\left(\alpha_{i}, \Delta_{i}\right)$ є рівнозначними і представляють один і той же ваговий коефіцієнт $C_{\beta_{i}}^{\alpha_{i}}$.

Будь-яке двійкове біноміальне число $X_{j}$ можна представити як упорядковану $q$-елементну вибірку $S_{X_{j}}$ ( $q$-кортеж) 3 множини $C$ всіх вибірок вагових коефіцієнтів, можливих для біноміальних чисел з параметрами $n$ i $k$ :

$$
S_{X_{j}}=\left(\left(\alpha_{i}, \Delta_{i}\right)^{(1)}, \ldots,\left(\alpha_{i}, \Delta_{i}\right)^{(u)}, \ldots,\left(\alpha_{i}, \Delta_{i}\right)^{(q)}\right),
$$

де $0 \leq q \leq k, \quad u=\overline{1, q}, \quad 1 \leq i \leq n-1, \quad S_{X_{j}} \in C$. При цьому, якщо $q=0$, то кортеж $S_{X_{j}} \in$ пустим і відповідає числу $X_{j}=00 \ldots 0$.

3 тим, щоб перейти до розгляду множини $C$ вибірок вагових коефіцієнтів $C_{\beta_{i}}^{\alpha_{i}}$ наведемо без доведення наступне твердження.

Твердження 1. Область розміщення $u$-ї одиниці, де $u=\overline{1, q}$, в запису двійкового $(n, k)$ біноміального числа $X_{j}=x_{1} x_{2} \ldots x_{i} \ldots x_{n-1} \quad$ задається нерівністю виду:

$$
u \leq i \leq n-k+(u-1) .
$$

Беручи до уваги вид $q$-елементної вибірки (9), множину $C$ можливих кортежів вагових коефіцієнтів можна представити як теоретико-множинний добуток:

$$
C=U_{1} \times U_{2} \times \ldots \times U_{u} \times \ldots \times U_{q},
$$

де $U_{1}=\left\{\left(\alpha_{i}, \beta_{i}\right): \alpha_{i}=k\right\}$ - множина біноміальних коефіцієнтів з верхнім параметром $\alpha_{i}=k$, можливих для двійкового біноміального числа $X_{j}$, де
$1 \leq i \leq n-k ; \quad U_{u}=\left\{\left(\alpha_{i}, \beta_{i}\right): \alpha_{i}=k-u+1, \beta_{i}<\beta_{i}^{(u-1)}\right.$, $\left.\left(k-u+2, \beta_{i}^{(u-1)}\right) \in U_{u-1}\right\}$ - множина біноміальних коефіцієнтів, у яких верхній параметр $\alpha_{i}=k-u+1$, а нижній повинен задовольняти умові, що кожна наступна $u$-a одиниця, яка відповідає парі $\left(k-u+1, \beta_{i}\right)$, повинна розміщуватися в розрядах запису біноміального числа $X_{j}$ правіше попередньої $(u-1)$-ї двійкової одиниці, де $u=\overline{1, q}$ і $u \leq i \leq n-k+(u-1)(10)$.

Твердження 1 відображає обмеження на компоненти $\left(\alpha_{i}, \beta_{i}\right)^{(u)} q$-елементних вибірок вагових коефіцієнтів з множини $C$. Дані обмеження мають структурний характер, оскільки слідують з структури двійкового біноміального числа. Для кожної $u$-ї одиниці існує дозволений діапазон номерів розрядів (10) i, відповідно, заборонені номери розрядів двійкового біноміального числа $X_{j}$.

Оскільки значення вагових коефіцієнтів залежать від двох параметрів $\alpha_{i}$ та $\Delta_{i}$, то зручною моделлю для представлення множини $C$ (11) і самих кортежів $S_{X_{j}}(9) \epsilon$ матриці, координатами елементів яких є параметр $\alpha_{i}$ i зміщення $\Delta_{i}$ параметрів біноміальних коефіцієнтів.

Матриці, які відображають кортежі $S_{X_{j}} \in C$ біноміальних чисел $X_{j} \in X$, виявляються зручними не лише для їх подання, а й для проведення операцій над самими біноміальними числами. Таким чином, в роботі пропонується операцію підсумовування біноміальних чисел $X_{j}^{\prime}$ и $X_{j}^{\prime \prime}$ проводити, застосовуючи матричне представлення відповідних їм кортежів $S_{X_{j}^{\prime}}$ і $S_{X_{j}^{\prime \prime}}$.

Розмір матриці, елементами якої є коефіцієнти $C_{\alpha_{i}+\Delta_{i}}^{\alpha_{i}}$, по параметру $\alpha_{i}$ представляється відомим, так як $1 \leq \alpha_{i} \leq k$. Щоб визначити розмір матриці біноміальних коефіцієнтів по параметру $\Delta_{i}$, наведемо без доведення наступне твердження.

Твердження 2. Значення зміщення $\Delta_{i}$ параметрів вагових коефіцієнтів $C_{\alpha_{i}+\Delta_{i}}^{\alpha_{i}}$ двійкових $(n, k)$ біноміальних чисел змінюється в межах:

$$
0 \leq \Delta_{i} \leq n-k-1 \text {. }
$$

На підставі того, що $\alpha=\alpha_{i}=\overline{k, 1}$ і згідно (11) $\Delta=\beta_{i}-\alpha_{i}=\overline{n-k-1,0}$, введемо для множини $C$ матрицю $\left\|C_{\alpha+\Delta}^{\alpha}\right\|$ біноміальних коефіцієнтів, число 
стовпчиків якої $є k$, а строк $(n-k)$. $q$-елементна упорядкована вибірка $S_{X_{j}}$, що відповідає двійковому біноміальному числу $X_{j}$, буде відображатися $(0,1)$-матрицею, побудованій на основі матриці вагів $\left\|C_{\alpha+\Delta}^{\alpha}\right\|$ біноміальної числової функції (1):

\begin{tabular}{|c|c|c|c|c|c|}
\hline$C_{n-1}^{k}$ & $C_{n-2}^{k-1}$ & $\ldots$ & $C_{\alpha+(n-k-1)}^{\alpha}$ & $\ldots$ & $C_{n-k}^{1}$ \\
\hline$C_{n-2}^{k}$ & $C_{n-3}^{k-1}$ & $\ldots$ & $C_{\alpha+(n-k-2)}^{\alpha}$ & $\ldots$ & $C_{n-k-1}^{1}$ \\
\hline$\ldots$ & $\ldots$ & $\ldots$ & $\ldots$ & $\ldots$ & $\ldots$ \\
\hline$C_{k+\Delta}^{k}$ & $C_{k-1+\Delta}^{k-1}$ & $\ldots$ & $C_{\alpha+\Delta}^{\alpha}$ & $\ldots$ & $C_{1+\Delta}^{1}$ \\
\hline$\ldots$ & $\ldots$ & $\ldots$ & $\ldots$ & $\ldots$ & $\ldots$ \\
\hline$C_{k}^{k}$ & $C_{k-1}^{k-1}$ & $\ldots$ & $C_{\alpha}^{\alpha}$ & $\ldots$ & $C_{1}^{1}$ \\
\hline
\end{tabular}

Наявність вагового коефіцієнту $C_{\beta_{i}}^{\alpha_{i}}$ в запису біноміального числа $X_{j}$ в $(0,1)$-матриці (12) вказується розміщенням одиниці у відповідному осередку $(\alpha, \Delta)$. Решта осередків $(\alpha, \Delta)(0,1)$-матриці при цьому заповнюються нулями.

В якості визначальних властивостей $(0,1)$ матриць двійкових $(n, k)$-біноміальних чисел $X_{j}$ можна сформулювати наступні.

1. Координати $\alpha$ одиничних осередків $(\alpha, \Delta)$, які відносяться до двійкового біноміального числа $X_{j}$, повинні складати строго монотонно спадну послідовність значень:

$$
k>k-1>k-2>\ldots>1,
$$

або іiі префіксну частину, починаючи зі значення $\alpha=k$. Це означає, що у стовпчиках $(0,1)$-матриці буде присутня тільки одна одиниця.

2. Для сусідніх по стовпчикам осередків матриці $з$ координатами $\left(\alpha+1, \Delta^{\prime \prime}\right)$ i $\left(\alpha, \Delta^{\prime}\right)$, які відносяться до двійкового біноміального числа $X_{j}$, має дотримуватися нерівність:

$$
\Delta^{\prime}<\Delta^{\prime \prime}+1 .
$$

Дана властивість доповнює попередню і відображає той факт, що строго монотонно спадна послідовність верхніх параметрів $\alpha_{i}$ біноміальних коефіцієнтів $C_{\beta_{i}}^{\alpha_{i}}$ або іiі префіксна частина (13) повинна відповідати строго монотонній спадній послідовності нижніх параметрів $\beta_{i}$ або іiі відповідній префіксній частині:

де $u=\overline{1, q}$.

$$
\beta_{i}^{(1)}>\beta_{i}^{(2)}>\ldots>\beta_{i}^{(u)}>\ldots . . \beta_{i}^{(q)},
$$

Іншими словами, кожний наступний одинич- ний осередок в $(0,1)$-матриці не повинен розташовуватися вище за рядком попереднього осередку, який містить одиницю.

Якщо складаються два двійкових біноміальних числа $X^{\prime}$ i $X^{\prime \prime}$, кожне $з$ яких характеризується $q$ кортежом вагових коефіцієнтів $S_{X_{j}^{\prime}}$ і $S_{X_{j}^{\prime \prime}}$ відповідно, то результатом буде двійкове біноміальне число $Z$, котре повинно також представлятися $q$ кортежом $S_{Z}$ вигляду (9). При цьому довжина $q$ кортежів для біноміальних чисел $X^{\prime}, X^{\prime \prime}$ і $Z$ може бути різною. Результат підсумовування $Z$ також повинен представлятися відповідною $(0,1)$ матрицею (12) двійкового біноміального числа, що відповідає властивостям (13) та (14).

3 урахуванням симетрії $X^{\prime}+X^{\prime \prime}=X^{\prime \prime}+X^{\prime}$ і того, що розглядається випадок тільки двох доданків, вихідною для отримання результату $Z$ буде неупорядкована вибірка:

$$
\begin{gathered}
G=\left[S_{X^{\prime}}, S_{X^{\prime \prime}}\right]= \\
=\left[\begin{array}{c}
\left(\left(\alpha_{i}, \Delta_{i}\right)_{X^{\prime}}^{(1)}, \ldots,\left(\alpha_{i}, \Delta_{i}\right)_{X^{\prime}}^{(u)}, \ldots,\left(\alpha_{i}, \Delta_{i}\right)_{X^{\prime}}^{\left(q_{X^{\prime}}\right)}\right), \\
\left(\left(\alpha_{i}, \Delta_{i}\right)_{X^{\prime \prime}}^{(1)}, \ldots,\left(\alpha_{i}, \Delta_{i}\right)_{X^{\prime \prime}}^{(h)}, \ldots,\left(\alpha_{i}, \Delta_{i}\right)_{X^{\prime \prime}}^{\left(q_{X^{\prime \prime}}\right)}\right)
\end{array}\right],
\end{gathered}
$$

де $\left(\alpha_{i}, \Delta_{i}\right)_{X^{\prime}}^{(u)},\left(\alpha_{i}, \Delta_{i}\right)_{X^{\prime \prime}}^{(h)}-$ вагові коефіцієнти, які відносяться до двійкових біноміальних чисел $X^{\prime}$ i $X^{\prime \prime}$ відповідно. Додатково умовимося, що біноміальні числа $X^{\prime}, Y^{\prime \prime} \in X$, котрі відповідають елементам вибірки $G$, при підсумовуванні повинні приводити до двійкового біноміального числа $Z$ з тієї ж самої множини $X$.

Множина $M$ всіх пар $G$ представляє собою добуток множин $C q$-елементних вибірок вагових коефіцієнтів біноміальних чисел:

$$
M=C \times C=C^{2} .
$$

Відповідно до (15) процес складання двійкових біноміальних чисел $X^{\prime}$ i $X^{\prime \prime}$ полягає в реалізації відображення $\varphi: C^{2} \rightarrow C$ множини $C^{2}$ пар $G=\left[S_{X^{\prime}}, S_{X^{\prime \prime}}\right]$ на множину $C q$-елементних кортежів $S_{Z}$ вагових коефіцієнтів, які відповідають результату $Z$ підсумовування. 3 огляду на кінцевий розмір $1 \leq i \leq n-1$ розрядної сітки двійкових біноміальних чисел, які складаються, буде розглядатися математична модель біноміального складання на основі звуження $\varphi^{\prime}: M^{\prime} \rightarrow C$ початкового відображення $\varphi: C^{2} \rightarrow C$ при виконанні $M^{\prime} \subseteq C^{2} \quad$ i $\varphi^{\prime}(G)=\varphi(G)$ для всіх пар $G \in M^{\prime}$, де

$$
M^{\prime}=\left\{G \in C^{2} / \sum_{X^{\prime}} C_{\beta_{i}}^{\alpha_{i}}+\sum_{X^{\prime \prime}} C_{\beta_{i}}^{\alpha_{i}}<C_{n}^{k}\right\} .
$$


Вид множини $C$ дозволяє вивести ознаки завершення операції біноміального підсумовування, визначити і обгрунтувати набір використовуваних перетворень над ваговими коефіцієнтами, які засновані на відомих комбінаторних співвідношеннях і властивості чисел сполучень [25]:

1. Перетворення $V$ переносу:

$$
\begin{aligned}
& C_{n-i}^{k-q_{i}}=C_{n-(i+1)}^{k-q_{i}}+C_{n-(i+2)}^{\left(k-q_{i}\right)-1}+\ldots \\
& \ldots+C_{n-\left(i+k-q_{i}\right)}^{1}+C_{n-\left(i+k-q_{i}+1\right)}^{0}
\end{aligned} .
$$

2. Перетворення $W$ зрушення:

$$
C_{\alpha_{i}}^{\alpha_{i}}=C_{\gamma_{i}}^{\gamma_{i}}=C_{\chi_{i}}^{0}
$$

де $\alpha_{i} \neq \gamma_{i} \neq \chi_{i}, 1 \leq \alpha_{i}, \gamma_{i}, \chi_{i} \leq k$.

3. Перетворення $B$ симетрії:

$$
C_{\beta_{i}}^{\alpha_{i}}=C_{\beta_{i}}^{\beta_{i}-\alpha_{i}}
$$

4. Перетворення $D$ розкладання:

$$
C_{\beta_{i}}^{\alpha_{i}}=C_{\beta_{i}-1}^{\alpha_{i}}+C_{\beta_{i}-1}^{\alpha_{i}-1} .
$$

Матриця $\left\|C_{\alpha+\Delta}^{\alpha}\right\|$ для неупорядкованої вибірки $G=\left[S_{X^{\prime}}, S_{X^{\prime \prime}}\right]$, яка містить обидва доданки $X^{\prime}$ и $X^{\prime \prime}$, буде характеризуватися тим, що в іiі осередках $(\alpha, \Delta)$ можуть розташовуватися вже не одна, а декілька одиниць, на відміну від $(0,1)$-матриць. Це пов'язано з тим, що, по-перше, в своєму представленні двійкове біноміальне число $X^{\prime}$ може мати вагові коефіцієнти, які будуть співпадати 3 коефіцієнтами двійкового біноміального числа $X^{\prime \prime}$, а, по-друге, однакові біноміальні коефіцієнти можуть з'явитися в результаті перетворень (16)-(19), що проводяться в процесі біноміального складання. Крім того, на відміну від $(0,1)$-матриць двійкових біноміальних чисел в матрицю вагів $\left\|C_{\alpha+\Delta}^{\alpha}\right\|$, що характеризує вибірку $G$, необхідно ввести додатковий стовпчик 3 $\alpha=0$, в осередках якого будуть розміщуватися одиниці, які завершують серії одиниць.

Матриця вагів $\left\|C_{\alpha+\Delta}^{\alpha}\right\|$, яка має розмір $(k+1) \times(n-k) \quad$ і яка відображує вибірку $G=\left[S_{X^{\prime}}, S_{X^{\prime \prime}}\right]$, де $S_{X^{\prime}}$ и $S_{X^{\prime \prime}}-q$-елементні кортежі вагових коефіцієнтів двійкових біноміальних чисел $X^{\prime}$ и $X^{\prime \prime}$, які додаються один до одного, буде називатися матрицею біноміального складання i позначатися як $(0,11 \ldots 1)$-матриця:

\begin{tabular}{|c|c|c|c|c|c|}
\hline$C_{n-1}^{k}$ & $\ldots$ & $C_{\alpha+(n-k-1)}^{\alpha}$ & $\ldots$ & $C_{n-k}^{1}$ & $C_{n-k-1}^{0}$ \\
\hline$C_{n-2}^{k}$ & $\ldots$ & $C_{\alpha+(n-k-2)}^{\alpha}$ & $\ldots$ & $C_{n-k-1}^{1}$ & $C_{n-k-2}^{0}$ \\
\hline$\ldots$ & $\ldots$ & $\ldots$ & $\ldots$ & $\ldots$ & $\ldots$ \\
\hline$C_{k+\Delta}^{k}$ & $\ldots$ & $C_{\alpha+\Delta}^{\alpha}$ & $\ldots$ & $C_{1+\Delta}^{1}$ & $C_{\Delta}^{0}$ \\
\hline$\ldots$ & $\ldots$ & $\ldots$ & $\ldots$ & $\ldots$ & $\ldots$ \\
\hline$C_{k}^{k}$ & $\ldots$ & $C_{\alpha}^{\alpha}$ & $\ldots$ & $C_{1}^{1}$ & $C_{0}^{0}$ \\
\hline
\end{tabular}

Відповідно, процес складання двійкових біноміальних чисел можна представити як процес формування серій двійкових одиниць 3 метою одержання на основі (16) вагових коефіцієнтів з найбільшим значенням $\Delta_{i}=\beta_{i}-\alpha_{i}$, де $i=\overline{1, n-1}$.

В якості прикладу наведемо $(0,1)$-матриці (12) рівномірних двійкових біноміальних чисел $X^{\prime}=01101100$ и $X^{\prime \prime}=00101011$ двійкової $(9,4)$ біноміальної системи числення:

$$
\left\|X^{\prime}\right\|=\begin{array}{|l|l|l|l|}
\hline 0 & 0 & 0 & 0 \\
\hline \mathbf{1} & \mathbf{1} & 0 & 0 \\
\hline 0 & 0 & \mathbf{1} & \mathbf{1} \\
\hline 0 & 0 & 0 & 0 \\
\hline 0 & 0 & 0 & 0 \\
\hline
\end{array},\left\|X^{\prime \prime}\right\|=\begin{array}{ll|l|l|l|}
0 & 0 & 0 & 0 \\
\hline 0 & 0 & 0 & 0 \\
\hline \mathbf{1} & 0 & 0 & 0 \\
\hline 0 & \mathbf{1} & 0 & 0 \\
\hline 0 & 0 & \mathbf{1} & \mathbf{1} \\
\hline
\end{array},
$$

а також вихідну $(0,11 \ldots 1)$-матрицю (20) біноміального складання вказаних чисел $X^{\prime}$ и $X^{\prime \prime}$ :

$$
\left\|X^{\prime}+X^{\prime \prime}\right\|=\begin{array}{|l|l|l|l|l|}
\hline 0 & 0 & 0 & 0 & 0 \\
\hline \mathbf{1} & \mathbf{1} & 0 & 0 & 0 \\
\hline \mathbf{1} & 0 & \mathbf{1} & \mathbf{1} & 0 \\
\hline 0 & \mathbf{1} & 0 & 0 & 0 \\
\hline 0 & 0 & \mathbf{1} & \mathbf{1} & 0 \\
\hline
\end{array},
$$

над осередками якої для отримання результату, двійкового біноміального числа $Z$ необхідно провести перетворення $V$ переносу (16), $W$ зрушення (17), $B$ симетрії (18) та $D$ розкладання (19).

\section{Висновки}

Представлена матрична модель біноміального складання, а також перетворення переносу, зрушення, симетрії і розкладання над осередками матриці $є$ основою для побудови математичної моделі, теоретичних та прикладних алгоритмів не тільки підсумовування двійкових біноміальних чисел, але і інших арифметичних операцій - віднімання, множення і ділення, тобто власне самої машинної біноміальної арифметики для інформаційно-керуючих систем.

Розробка і впровадження такої арифметики в інформаційно-керуючих системах, біноміальних пристроях та системах для вирішення спеціалізованих завдань дозволяє розширити можливості щодо 
застосування двійкових біноміальних систем числення, створювати нові методи кодування і генерування комбінаторних об'єктів, в повній мірі реалізовувати інформаційну технологію обробки даних на основі двійкових біноміальних чисел. Приклад можливого ефективного використання біноміальної арифметики демонструється на наведених в даній роботі моделях біноміального додавання і множення кодів-сполучень, які засновані на переході від розглянутих кодів-сполучень до двійкових біноміальних чисел, що становлять їх внутрішню структуру.

\section{Список літератури}

1. Борисенко О.А. Число і системи числення в електронних цифрових системах / О.А. Борисенко // Вісник Сумського державного університету. Серія Технічні науки. - 2007. - № 4. - С. 71-76.

2. Гашков С.Б. Системы счисления и их применение / С.Б. Гашков. - М.: Изд-во МЦНМО, 2004. -52 с.

3. Фомин С.В. Системы счисления / С.В. Фомин. - М.: Гл. ред. физ.-мат. лит., 1987. - 48 с.

4. Effective Data Processing in Coding, Digital Signals and Cryptography: monograph / V. Krasnobaev, A. Kuznetsov, S. Rassomakhin, A. Zamula, S. Koshman, S. Kavun. - Minden, Nevada, USA: ASC Academic Publishing, 2018. - 352 p.

5. Stakhov A. A History, the Main Mathematical Results and Applications for the Mathematics of Harmony / A. Stakhov // Applied Mathematics. - 2014. - Vol. 5, No. 3. - P. 363-386. https://doi.org/10.4236/am.2014.53039.

6. Поляков В.И. Применение факториальной системы для решения комбинаторных задач / В.И. Поляков, В.И. Скорубский, Ю.В. Экало // Изв. вузов. Приборостроение. - 2015. - Т. 58, № 6. - С. 436-442. https://doi.org/10.17586/00213454-2015-58-6-436-442.

7. Кулик І.А. Розробка інформаційно-керуючих систем на основі двійкової біноміальної системи числення / І.А. Кулик, М.С. Шевченко // Системи обробки інформації. $-2020 . \quad$ № 2(161). $\quad$ - C. 78-85. https://doi.org/10.30748/soi.2020.161.09.

8. Борисенко А.А. Биномиальное кодирование: монография / А.А. Борисенко, И.А. Кулик. - Сумы: Изд-во СумГУ, 2010. $-206 \mathrm{c}$.

9. Борисенко А.А. Биномиальный счет. Теория и практика: монография / А.А. Борисенко. - Сумы: ИТД “Университетская книга", 2004. - 170 с.

10. Рейнгольд Э. Комбинаторные алгоритмы. Теория и практика / Э. Рейнгольд, Ю. Нивергелът, Н. Део. - М.: Мир, 1980. $-476 \mathrm{c}$.

11. Кнут Д.Э. Искусство программирования, том 4, А. Комбинаторные алгоритмы, часть 1: Пер. с англ. / Д.Э. Кнут. - М.: Вильямс, 2013. - 960 с.

12. Савельев А.Я. Прикладная теория цифровых автоматов / А.Я. Савельев. - М.: Высшая школа, 1987. - 272 с.

13. Esmaeili M. A new class of Fibonacci sequence based error correcting codes / M. Esmaeili, M Moosavi, T.A. Gulliver // Cryptogr. Commun. - 2017. - 9 - P. 379-396. https://doi.org/10.1007/s12095-015-0178-x.

14. Circuit Synthesis from Fibonacci Decision Diagrams / Radomir S. Stankovic', Jaakko Astola, Milena Stankovic', Karen Egiazarian // VLSI Design. - 2002. - Vol. 14(1). - P. 23-34. https://doi.org/10.1080/10655140290009783.

15. Борисенко О.А. Електронна система генерації перестановок на базі факторіальних чисел / О.А. Борисенко, I.А. Кулик, О.Є. Горячев // Вісник СумДУ, Серія Технічні науки. - 2007. - № 1. - С. 183-188. $832 \mathrm{c}$.

16. Кнут Д.Э. Искусство программирования, т. 2. Получисленные алгоритмы / Д.Э. Кнут. - М.: Вильямс, 2018. -

17. Модели и методы обработки данных в системе остаточных классов: монография / С.А. Кошман, В.А. Краснобаев, С.А. Мороз, В.Н. Курчанов, А.С. Янко. - Харьков: ООО “В деле”, 2017. - 197 с.

18. Krasnobayev V.A. A Method for Arithmetic Comparison of Data Represented in a Residue Number System / V.A. Krasnobayev, A.S. Yanko, S.A. Koshman // Cybern. Syst. Anal. - 2016. - No. 52. - P. $145-150$. https://doi.org/10.1007/s10559-016-9809-2.

19. Кулик И.А. К вопросу о сложении биномиальных чисел / И.А. Кулик // Вісник Сумського державного університету. Серія Технічні науки. - 2012. - № 3. - С. 101-109. $152 \mathrm{c}$.

20. Борисенко А.А. Биномиальный счет и счетчики: монография / А.А. Борисенко. - Сумы: Изд-во СумГУ, 2008. -

21. Кулик И.А. Метод оценки границ применения сжатия на основе двоичных биномиальных чисел / И.А. Кулик, А.И. Новгородцев, М.С. Шевченко // Системи обробки інформації. - 2019. - № 2(157). - С. 57-62. https://doi.org/ 10.30748/soi.2019.157.07.

22. Кулик И.А. Генерирование кодов-сочетаний для решения информационных задач ИУС / И.А. Кулик, Е.М. Скордина, С.В. Костель // АСУ и приборы автоматики. Всеукраинский межведомственный сборник. - 2011. № 155 . - С. 15-23.

23. Сачков В.Н. Введение в комбинаторные методы дискретной математики / В.Н. Сачков. - М.: Наука, Гл. ред. физ.-мат. лит., 1982. - 384 с.

24. Феферман С. Числовые системы. Основания алгебры и анализа / С. Феферман. - М.: Наука, 1971. -440 с.

25. Anderson Ja.A. Discrete mathematics with combinatorics / Ja.A. Anderson. - Prentice-Hall, Inc., 2001. - 960 p.

\section{References}

1. Borysenko, O.A. (2007), "Chyslo i systemy chyslennia v elektronnykh tsyfrovykh systemakh" [A number and number systems in electronic digital systems], Bulletin of Sumy state university, Series "Tehnichni nauki", No. 4, Sumy state university, pp. 71-76.

2. Gashkov, S.B. (2004), "Sistemy schislenija i ih primenenie" [Number systems and their application], Izd-vo MCNMO, Moscow, $52 \mathrm{p}$. 
3. Fomin, S.V. (1987), "Sistemy schislenija" [Number systems], Gl. red. fiz.-mat. lit., Moscow, 48 p.

4. Krasnobaev, V., Kuznetsov, A., Rassomakhin, S., Zamula, A., Koshman, S. and Kavun, S. (2018), Effective Data Processing in Coding, Digital Signals and Cryptography: monograph, ASC Academic Publishing, Minden, Nevada, USA, 352 p.

5. Stakhov, A. (2014), A History, the Main Mathematical Results and Applications for the Mathematics of Harmony, Applied Mathematics, Vol. 5, No. 3, pp. 363-386. https://doi.org/10.4236/am.2014.53039.

6. Polyakov, V.I., Skorubsky, V.I. and Ekalo, Yu.V. (2015), "Primenenie faktorial'noj sistemy dlja reshenija kombinatornyh zadach" [Application of factorial system to combinatorial problems solving], Izvestiya Vysshikh Uchebnykh Zavedeniy, Priborostroenie, Vol. 58, No. 6, pp. 436-442. https://doi.org/10.17586/0021-3454-2015-58-6-436-442.

7. Kulyk, I.A. and Shevchenko, M.S. (2020), "Rozrobka informatsiino-keruiuchykh system na osnovi dviikovoi binomialnoi systemy chyslennia" [Development of information-management systems on basis of binary binomial number systems], Information Processing Systems, No. 2(161), pp. 78-85. https://doi.org/10.30748/soi.2020.161.09.

8. Borysenko, A.A. and Kulyk, I.A. (2010), “Binomial'noe kodirovanie: monografija” [Binomial coding], Sumy State University, Sumy, $206 \mathrm{p}$.

9. Borysenko, A.A. (2004), "Binomial'nyj schet. Teorija i praktika: monografija" [Binomial count. Theory and practice], ITD “Universitetskaja kniga”, Sumy, 170 p.

10. Rejngol'd, Je., Nivergelt, Ju. and Deo, N. (1980), “Kombinatornye algoritmy. Teorija i praktika” [Combinatorial algorithms. Theory and practice], Mir, Moscow, $476 \mathrm{p}$.

11. Knut, D.Je. (2013), "Iskusstvo programmirovanija, t. 4, A. Kombinatornye algoritmy, chast' 1" [The art of computer programming, V. 4, A. Combinatorial algorithms, part 1], Vil'jams, Moscow, $960 \mathrm{p}$.

12. Savel'ev, A.Ja. (1987), "Prikladnaja teorija cifrovyh avtomatov" [Applied theory of digital automata], Vysshaja shkola, Moscow, $272 \mathrm{p}$.

13. Esmaeili, M., Moosavi, M. and Gulliver, T.A. (2017), A new class of Fibonacci sequence based error correcting codes, Cryptogr. Commun., No. 9, pp. 379-396. https://doi.org/10.1007/s12095-015-0178-x.

14. Stankovic', S. R., Astola, Ja. and Stankovic', M. (2002), Circuit Synthesis from Fibonacci Decision Diagrams, VLSI Design, Vol. 14(1), pp. 23-34. https://doi.org/10.1080/10655140290009783.

15. Borysenko, O.A. (2007), "Elektronna systema heneratsii perestanovok na bazi faktorialnykh chysel" [Electronic generation permutations system on basis of factorial numbers], Bulletin of Sumy state university, Series Tehnichni nauki, No. 1, Sumy state university, pp. 183-188.

16. Knut, D.Je. (2018), "Iskusstvo programmirovanija, t. 2. Poluchislennye algoritmy" [The art of computer programming, V. 2, Seminumerical Algorithms], Vil'jams, Moscow, 832 p.

17. Koshman, S.A., Krasnobaev, V.A., Moroz, S.A., Kurchanov, V. N. and Janko, A.S. (2017), "Modeli i metody obrabotki dannyh $v$ sisteme ostatochnyh klassov: monografija" [Models and methods of data processing in a system of residual classes], Kharkiv, $197 \mathrm{p}$.

18. Krasnobayev, V.A., Yanko, A.S., and Koshman, S.A. (2016), Method for Arithmetic Comparison of Data Represented in a Residue Number System, Cybern. Syst. Anal., No. 52, pp. 145-150. https://doi.org/10.1007/s10559-016-9809-2.

19. Kulyk, I.A. (2012), "K voprosu o slozhenii binomial'nyh chisel" [To the problem on addition of binomial numbers], Bulletin of Sumy state university, Series Tehnichni nauki, No. 3, Sumy state university, pp. 101-109.

20. Borysenko, A.A. (2008), "Binomial'nyj schet i schetchiki: monografija" [Binomial count and counters], Izd-vo SumGU, Sumy, $152 \mathrm{p}$.

21. Kulyk, I.A., Novhorodtsev, A.I. and Shevchenko, M.S. (2019), "Metod ocenki granic primenenija szhatija na osnove dvoichnyh binomial'nyh chisel" [Method for borders estimation of compression on basis of binary binomial numbers], Information Processing Systems, No. 2(157), pp. 57-62. https://doi.org/ 10.30748/soi.2019.157.07.

22. Kulyk, I.A., Skordina, E.M., and Kostel, S.V. (2011), "Generirovanie kodov-sochetanij dlya resheniya informacionnyh zadach IUS" [Generation of code-combinations for solving MIS's information tasks], Automated management systems and automation devices, No. 155, pp. 15-23.

23. Sachkov, V.N. (1982), "Vvedenie v kombinatornye metody diskretnoj matematiki" [Introduction into combinatorial methods of discrete mathematics], Nauka, Gl. red. fiz.-mat. lit., Moscow, 384 p.

24. Feferman, S. (1971), "Chislovye sistemy. Osnovanija algebry i analiza" [Numeric systems. Foundations of algebra and analysis], Nauka, Moscow, $440 \mathrm{p}$.

25. Anderson, Ja.A. (2001), Discrete mathematics with combinatorics, Prentice-Hall, Inc., 960 p.

Надійшла до редколегії 10.02.2021

Схвалена до друку 02.03.2021

\section{Відомості про авторів:}

\section{Кулик Ігор Анатолійович}

кандидат технічних наук доцент

Сумського державного університету, Суми, Україна

https://orcid.org/0000-0003-2403-8671

\author{
Шевченко Марина Сергї̈вна \\ аспірант \\ Сумського державного університету, \\ Суми, Україна \\ https://orcid.org/0000-0002-1434-5996
}

\author{
Information about the authors: \\ Igor Kulyk \\ Candidate of Technical Sciences Senior Lecturer \\ of Sumy State University, \\ Sumy, Ukraine \\ https://orcid.org/0000-0003-2403-8671
}




\title{
МАТРИЧНАЯ МОДЕЛЬ СЛОЖЕНИЯ ДВОИЧНЫХ БИНОМИАЛЬНЫХ ЧИСЕЛ
}

\author{
И.А. Кулик, М.С. Шевченко
}

В статье предлагается матричная модель сложения биномиальных чисел, генерируемых двоичными биномиальными системами счисления. Модель биномиального сложения использует матричное представление чисел и преобразования переноса, сдвига, симметрии, разложения над содержимым ячеек матрииы суммирования, каждая из которых соответствует весовому коэффиииенту биномиальной числовой функиии. Указанные преобразования основаны на известных комбинаторных соотнотениях. Приведены модели арифметических действий над кодами-сочетаниями на основе реализаиии сложения и умножения двоичных биномиальных чисел.

Ключевые слова: двоччные биномиальные числа, биномиальная арифметика, матрица биномиального сложения, преобразования ячеек матрищы.

\section{MATRIX MODEL OF BINARY BINOMIAL NUMBERS ADDITION}

\author{
I. Kulyk, M. Shevchenko
}

In the paper the matrix model of addition for binomial numbers which are generated by binary binomial number systems is proposed. To obtain such an addition model the matrix model for representing the binary binomial numbers is developed. The points of their matrixes correspond to weighting coefficients of a binomial numeric function, which represents numbers of combinations. For the purpose to construct and operate the binomial numbers matrix models easily the binomial coefficients are substituted for two-component tuples, which are composed by upper and lower parameters of numbers of combinations from a binomial numeric function. As opposed to the matrix model for binomial numbers the matrix models of binomial addition contain one more supplementary column for setting series of units that gives transfer unit to the next digit of the resulting binomial number. Besides the points of the binomial addition matrix can keep a few units, obtained from added binomial numbers, and as a result of conversions on contents of the matrix points. The model of the binomial addition uses transfer, shift, symmetry and expansion conversions, operating with the components of the corresponding tuples. Summing up of binary binomial numbers is the process of binary units series formation in order to receive the weighting coefficients with the largest difference of the components of the tuples on basis of the transfer conversions and the auxiliary ones of shift, symmetry and expansion of the contents of the binomial addition matrix points. The considered conversions are based on the well-known combinatory ratios. The models of arithmetic operations for code-combinations on basis of binomial addition and multiplication implementation with using the binary binomial numbers are given.

Keywords: binary binomial numbers, binomial arithmetic, binomial addition matrix, matrix points conversions. 